\title{
Études juridiques comparatives et internationalisation du droit (2002-2011)
}

\section{Mireille Delmas-Marty}

\section{(2) OpenEdition}

1 Journals

Édition électronique

URL : https://journals.openedition.org/annuaire-cdf/16074

DOI : $10.4000 /$ annuaire-cdf. 16074

ISBN : 978-2-7226-0572-5

ISSN : 2109-9227

Éditeur

Collège de France

Édition imprimée

Date de publication : 30 décembre 2020

Pagination : 633-635

ISBN : 978-2-7226-0516-9

ISSN : 0069-5580

\section{Référence électronique}

Mireille Delmas-Marty, «Études juridiques comparatives et internationalisation du droit (2002-2011) », L'annuaire du Collège de France [En ligne], 118 | 2020, mis en ligne le 01 avril 2021, consulté le 22 août 2022. URL : http://journals.openedition.org/annuaire-cdf/16074 ; DOI : https://doi.org/10.4000/ annuaire-cdf. 16074 


\title{
ÉTUDES JURIDIQUES COMPARATIVES \\ ET INTERNATIONALISATION DU DROIT (2002-2011)
}

\author{
Mireille DELMAS-MARTY \\ Membre de l'Institut (Académie des sciences morales et politiques), \\ professeur émérite
}

\section{RECHERCHE : VERS UN JUS COMMUNE UNIVERSALISABLE ? (SUITE)}

D'une part, j'ai poursuivi la recherche entreprise au sein du Collège de France, dont je coordonne la direction en partenariat avec l'Institut de sciences juridiques et philosophiques (CNRS/Paris 1), pour esquisser, à la lumière du passé et du présent, les conditions de validité d'un futur droit commun à vocation mondiale. Nous partons d'une hypothèse dynamique qui considère les pratiques de droit commun comme des processus transformateurs rapprochant les divers systèmes juridiques sans les fusionner. Ces processus se sont développés à diverses époques et dans diverses régions du monde. Leur réapparition par fragments dans le sillage de la mondialisation laisse entrevoir la possibilité d'un droit commun à vocation mondiale, sinon universel, du moins « universalisable ». L'objectif est triple : éclairer la notion de droit commun par une approche historique ; décrire l'émergence de fragments d'un droit commun mondial à l'heure de la mondialisation; esquisser les conditions théoriques et pratiques d'un futur droit commun « universalisable ». Après une réunion préparatoire en mai 2016, un séminaire a été consacré en avril 2017 à explorer les deux premiers objectifs. Une journée d'études s'est tenue le 27 novembre 2017 et des ateliers ( Terminologie » en quatre langues, dont l'arabe et le chinois et «Instruments juridiques ») ont été créés avec un groupe restreint de chercheurs au cours du premier semestre 2018. Ils visent à faciliter l'harmonisation des travaux réalisés et à amorcer la partie prospective de la recherche. Une prochaine rencontre de toute l'équipe est prévue en décembre 2018 dans la perspective d'une publication en 2019-2020.

D'autre part, la question des migrations m'a conduite à une analyse comparée portant sur les différences et les traits communs entre la gouvernance mondiale du climat et celle des migrations, m'inspirant un ouvrage à paraître en 2019 sur «l'humanisme juridique à la croisée des mondes ». Dans cet ouvrage, je prolonge notamment la réflexion engagée sur la mémoire et l'oubli, l'anticipation et l'imprévisibilité, proposée au sein du collège de France (groupe interdisciplinaire Memory).

Participation aux colloques et séminaires suivants: «Le devenir du monde occidentalo-centré. Réflexion sur loi et politique, droits de l'homme et culture au XXI ${ }^{\mathrm{e}}$ siècle », Maison franco-japonaise (Tokyo, septembre 2017, publication à paraître en version japonaise) ; "L'universalisation des droits de l'homme au XXI ${ }^{\mathrm{e}}$ siècle » (université Keiô, Tokyo, septembre 2017) ; «Repenser la notion d'ordre juridique à l'heure de l'Anthropocène » (université de Kyoto, septembre 2017) ; « D'un humanisme 
juridique de séparation à un humanisme d'interdépendance » $\left(\mathrm{XXXVI}^{\mathrm{e}}\right.$ Symposium international, Institut de Tomonubu Imamichi, pour Eco-Ethica, octobre 2017); colloque « Génocides, crimes de masse et violences extrêmes. Recherche, enseignement, engagements scientifiques» (Mission d'étude en France sur la recherche et l'enseignement des génocides et des crimes de masse, octobre 2017) ; "Faire bouger les lignes », conversation avec Gilles Clément, « Paysages en mouvement », (Goutelas, octobre 2017) ; colloque de clôture du programme « Ni guerre, ni paix. Les nouages contemporains du droit et de la violence », octobre 2017) ; colloque IEA et Collège International de philosophie de l'EHESS (Paris, octobre 2017); «Penser un monde poreux », colloque «Porosités du droit», American Society of Comparative Law, octobre 2017); "Penser l'ordre juridique à l'heure de l'Anthropocène», colloque «Agir en justice au nom des générations futures : une réalité grandissante vecteur de paix » (université de Caen Normandie, novembre 2017); "Vers un jus commune universalisable? », journée d'études dans le cadre du projet de recherche (Collège de France, novembre 2017) ; « Manifeste pour une mondialité apaisée », live de Mediapart (Grenoble, décembre 2017) ; colloque « Droits de l'homme et collectivités territoriales : entre le global et le local » (ISJPS, CNRS \& université Paris 1, Panthéon-Sorbonne, 6 décembre 2017); workshop « Interdépendances », projet Rencontres Occident-Orient (janvier 2018); "Principes pour une charte d'interdépendance: préserver les différences, reconnaître les interdépendances, promouvoir des solidarités planétaires », Journée du Collegium international (Lille, février 2018); «Objectifs communs, responsabilités différenciées, hospitalité universelle», Forum national pour une politique de développement renouvelée (MEAE, février 2018) ; "L'hospitalité peutelle devenir un principe juridique?», séminaire EHESS «Anthropologies de l'hospitalité » (mars 2018) ; «Vers un jus commune universalisable?», ateliers «Instruments juridiques » et «Terminologie », dans le cadre du projet de recherche (Collège de France, mars, mai puis juin 2018) ; « Mémoire, oubli, vérité, anticipation », «Memory Meeting» (Collège de France, avril 2018); colloque «Lectures du règlement instituant le Parquet européen » (ARPE, avril 2018) ; «Y-a-t-il des valeurs universelles ? » et «Au-delà de l'indignation, que pouvons-nous faire ?», festival «Étonnants voyageurs » (Nantes, mai 2018); colloque « The right use of the earth», programme de recherche Droit et responsabilité à l'heure de l'Anthropocène (Collège de France et PSL, mai 2018) ; «Rencontres Orient-Occident» (Château Mercier, Suisse, juin 2018) ; rencontre interacadémique «Ce que la misère donne à penser » (ATD-Quart Monde et Institut de France, juin 2018) ; «La guerre et la paix dans le droit constitutionnel moderne », congrès mondial AIDC-IACL «Conflits violents, consolidation de la paix et droit constitutionnel » (Séoul, juin 2018); «Marcher ensemble vers un droit commun mondial. L'avenir du droit à l'âge de globalisation » (université de Pékin, Chine, juin 2018).

\section{Publications}

\section{Articles et entretiens}

\section{Ouvrages collectifs}

Delmas-Marty M., «The ICC as a Work in Progress, for a World in Process », in M.M. de GuZman et D.M. Amann (dir.), Arcs of Global Justice: Essays in Honour of William A. Schabas, Oxford University Press, 2018. 
DELMAS-MARTY M., préface «Le principe de précaution et le paradoxe de l'anthropocène », in L. D'Ambrosio, G. Giudicelli-Delage et S. Manacorda, Principe de précaution et métamorphoses de la responsabilité, Mare et Martin, 2018.

Delmas-Marty M., «Soyons les gardiens de l'esprit des lois », in: Mai 2018. Dernier inventaire avant révolution, Paris, Les cahiers de l'asphalte (université Paris-Sorbonne), 2018.

Delmas-Marty M., « Lettre à Michel Rocard sur les misères du monde », in : Michel Rocard (livre-hommage à Michel Rocard), Flammarion, 2018.

Delmas-Marty M., « Manifeste pour une mondialité apaisée », in P. CHAmoiseau et M. LE BRIS (dir.), Osons la fraternité, Philippe Rey, 2018.

Delmas-Marty M., préface à V. Ohannessian et E. Pierrat, Code de la liberté d'expression. Textes et jurisprudence, Anne Rideau, 2018.

\section{Revues et blogs}

Delmas-Marty M., « Legal pluralism as a dynamic process in a moving world », 28 février 2018, http://jamesgstewart.com/legal-pluralism-as-a-dynamic-process-in-a-moving-world/.

Delmas-Marty M., « Où va le droit ? Entre pot au noir et pilotage automatique, le droit peut-il nous guider vers une mondialité apaisée ? », La semaine juridique, $\mathrm{n}^{\circ}$ 14, Lexis Nexis, 2 avril 2018.

Delmas-Marty M., «Créoliser la notion d'humanité », Courrier de l'Unesco, avriljuin 2018 .

DELMAS-MARTY M., «Quel droit pour un monde pluriel et instable ? », entretien, Études, $n^{\circ} 2018 / 6,2018$.

DELMAS-MARTY M., «Le principe de précaution : équilibrer innovation et conservation », entretien, Raison présente, $\mathrm{n}^{\circ}$ 206, 2018.

DELMAS-MARTY M., «Une course de vitesse. Entre décomposition, recomposition et dilution de l'ordre juridique », L'ENA hors des murs, $\mathrm{n}^{\circ} 481$ : Le droit et la justice aujourd'hui. Et demain?, 2018.

\section{Diffusion des travaux}

Entretien, Le Monde, «Loi antiterroriste : nous sommes passés de l'État de droit à l'État de surveillance », 14 octobre 2017 ; entretien ARD-Radio allemande, sur la loi antiterroriste, 17 octobre 2017 ; débat France Culture, «La rue est-elle victime de harcèlement judiciaire ? », Du grain à moudre, 23 octobre 2017 ; PhiloMag, « Gaston Bachelard vu par Mireille Delmas-Marty », 25 octobre 2017 ; Mediapart, « Manifeste pour une mondialité apaisée », 24 décembre 2017 ; entretien, La Croix, «Il faut bâtir une nouvelle gouvernance mondiale», 31 janvier 2018; tribune, Le Monde, «Migrants : faire de l'hospitalité un principe », 14 avril 2018; entretien RTBF, $A u$ bout du jour, sur Appel de Saint-Malo, 23 mai 2018 ; Le Monde, "Pour un principe d'hospitalité opposable aux États », 19 juin 2018 ; entretien, France culture, L'idée culture, sur Maria Helena Vieira da Silva, 16 juin 2018 ; entretien, TV5 Monde, 64 minutes, sur l'Appel de Saint Malo, 28 juillet 2018 ; débat France Culture, Du grain à moudre, «Politique migratoire : une affaire d'États ? », 27 août 2018. 